\title{
O sujeito homossexual como tema de aula: limites e oportunidades didáticas*
}

\author{
Alexandre Bortolini***
}

\section{Resumo}

Este trabalho foi desenvolvido a partir do material produzido por participantes de cursos de formação continuada em gênero, sexualidade e educação ofertados pela Universidade Federal do Rio de Janeiro. Analisa três atividades pedagógicas realizadas por profissionais de educação que se propuseram abordar a homossexualidade com suas turmas de educação básica, como parte do seu processo de aprendizado, em escolas públicas da região metropolitana do Rio de Janeiro. Tento aqui conduzir nossa reflexão crítica para, a partir dessas experiências, pensar sobre o caminho didático que elas apontam, qual seja: investir na descrição do sujeito homossexual/gay/lésbica como forma de trabalhar questões de gênero-sexualidade para além de uma perspectiva heteronormativa.

Palavras-chave: Educação, Diferença, Didática, Sexualidade, Homossexualidade.

* Recebido para publicação em 1 de abril de 2013, aceito em 7 de abril de 2015.

** Mestre em Educação pela PUC-Rio, trabalha na equipe da Coordenação-Geral de Direitos Humanos do Ministério da Educação, Brasília, DF, Brasil. bortolini.alexandre@gmail.com 
480 O sujeito homossexual como tema de aula

Homossexual Subject as Class Subject: Limits and Oportunities

\begin{abstract}
This work was developed from material produced by participants of continuing education courses on gender, sexuality and education offered by the Universidade Federal do Rio de Janeiro. Analyzes three pedagogical activities carried out by education professionals in public schools in the metropolitan area of Rio de Janeiro. Professionals who proposed to discuss homosexuality with their basic education classes as part of their own learning process. Here I attempt to conduct a critical reflection from these experiences, thinking about the didactic path that they point: to invest in the description of a homosexual/gay/lesbian subject as a way of overcoming a heteronormative perspective.
\end{abstract}

Key Words: Education, Diference, Didatics, Sexuality, Homosexuality. 


\section{Escola e Sexualidade}

O processo de construção de práticas, relações $e$ representações de gênero-sexualidade ${ }^{1}$ ocorre em diferentes espaços sociais: na família, na comunidade, no trabalho $e$, também, na escola. Mesmo que não figure em nenhuma diretriz educacional que a escola deve ensinar meninos a serem meninos e meninas a serem meninas, esse parece ser um conteúdo curricular assumido, trabalhado e priorizado pelas nossas escolas. Há muito mais sendo ensinado do que o que está escrito nos projetos político-pedagógicos e planejamentos de aula. A divisão por sexo nas aulas de Educação Física; o quadro de chamada e as filas de meninos e de meninas na educação infantil; as distinções sexistas nos uniformes; a forma como professoras e professores tratam $e$ as distintas expectativas que criam sobre alunos ou alunas; a tolerância da violência, verbal e até mesmo física, entre os meninos; as representações de homens e mulheres nos materiais didáticos; o lugar da (hetero)sexualidade no projeto pedagógico - $e$ a sua abordagem quase exclusivamente biológica; a preocupação em controlar a manifestação da sexualidade das adolescentes e dos adolescentes; a estigmatização que algumas vão vivenciar justamente por isso; a preocupação com possíveis "indícios" de homossexualidade no comportamento das crianças; a perseguição sistemática sofrida por qualquer pessoa cujos desejos, práticas ou corpos fujam da expectativa heteronormativa, tudo isso deixa claro o quanto a escola ensina, em diferentes momentos e espaços, sobre masculinidade, feminilidade, sexo, afeto, conjugalidade, família, etc. Esse currículo produz resultados: a escola participa ativamente na construção dos corpos $e$ identidades dos sujeitos que ali habitam - especialmente, mas não só, das suas e dos seus estudantes. A escola ensina também modos de agir e de ser.

1 A ideia não é propor um novo conceito, nem dizer que gênero e sexualidade são uma coisa só, apenas chamar atenção para a conexão intrínseca entre essas duas dimensões e inspirar em quem lê uma percepção mais integral. 
Obviamente as escolas brasileiras não têm um único jeito de ensinar sobre gênero-sexualidade, mas não faltam pesquisas (Auad, 2004; Carrara, 2005; Castro, 2004; Ferrari, 2007; Freitas, 2004; Furlani, 2005; Junqueira, 2009 e 2011; Lionço, 2009; Mazzon, 2009; Silva, 2007) que evidenciam um currículo marcado pelo sexismo, pelo racismo, pela misoginia e pela heteronormatividade. Não se trata de uma realidade exterior que simplesmente invade a escola, mas de uma dimensão da própria ação educativa que acontece ali dentro. A prática pedagógica e a ação institucional estão trabalhando ativamente na produção de práticas, representações e relações de gênero-sexualidade. E trabalhando de uma maneira bastante específica: investindo no reforço do binarismo de gênero - demarcando incisivamente a oposição entre masculino e feminino $e$ a hierarquia entre eles - e na heterossexualização compulsória - um pesado investimento para a produção de desejos e práticas heterossexuais, a fim de garantir uma única identidade sexual legitimada (Louro, 2001), marginalizando, invisibilizando e estigmatizando outras práticas e outros sujeitos. Portanto, a questão não está em se a escola deve ou não falar sobre gênero-sexualidade, mas sim em perceber como ela já fala onde, quando, por que caminhos e com que efeitos.

$\mathrm{O}$ que tantas pesquisadoras e pesquisadores apontam é que a heteronormatividade, o machismo, o racismo e a misoginia estão tão arraigados na nossa prática pedagógica que a sua superação não é simples, nem depende apenas de intencionalidade, embora ela seja fundamental. Superar essas marcas na nossa ação educativa é um processo demorado, de idas $e$ vindas, de erros e acertos, de aprendizados. Como diz Vera Candau, a construção de uma escola em que a diferença seja reconhecida e valorizada é "um processo permanente, sempre inacabado, marcado por uma deliberada intenção de promover uma relação democrática entre grupos e não unicamente uma coexistência pacífica num mesmo território" (Candau, 2010:99). Mas enquanto nossas práticas não mudam, elas seguem produzindo efeitos a todo o momento, hoje, agora, em milhões de pessoas que diariamente passam pelas escolas brasileiras. Superar 
tudo isso é uma necessidade imediata. Precisamos produzir urgentemente outras práticas. Práticas pedagógicas e de gestão que invistam na construção de outras representações e relações de gênero-sexualidade, que não hierarquizem, que não estigmatizem, que não violentem, que não matem. Práticas que não nos ensinaram na escola, nem na formação para a docência. Práticas que vamos ter de construir.

\section{Investindo em novas práticas}

Considerando o tamanho do nosso sistema de ensino, ainda são poucas as experiências educativas que investem na superação desse quadro que se pode identificar. No campo das políticas públicas, existem alguns ainda tímidos investimentos na transformação das práticas educativas no que diz respeito ao que elas ensinam quanto a gênero-sexualidade. Embora esse seja um campo de muitas tensões, avanços e retrocessos, iniciativas interessantes têm sido concretizadas em escolas, secretarias, redes de ensino e universidades, especialmente na área da formação de professores (Mello, 2010).

Uma dessas iniciativas aconteceu a partir de uma parceria entre a Universidade Federal do Rio de Janeiro e o Ministério da Educação, em 2010: a oferta de um curso de extensão presencial que tinha como foco as relações de gênero-sexualidade na escola, para profissionais de educação das redes públicas de ensino do Rio de Janeiro. Curso de cuja coordenação eu mesmo participei $e$ onde educadoras e educadores produziram o que seria a base para a pesquisa de mestrado que apresento neste artigo.

A universidade já vinha realizando, desde 2006, atividades de mobilização, produção de materiais didáticos e formação de profissionais de educação na área de gênero-sexualidade, numa abordagem que se propunha a produzir reflexão crítica e mobilizar para o enfrentamento à violência, o reconhecimento das diferenças e a construção de práticas educativas não heteronormativas. Atividades que se inseriam numa política 
específica do Ministério da Educação de financiamento de ações de formação para profissionais de educação.

Metodologicamente, a equipe do curso optou por investir, para além das atividades em sala, no desenvolvimento de atividades práticas na escola. Como parte do processo de aprendizagem as e os cursistas tinham de realizar atividades pedagógicas em seus espaços de trabalho - suas turmas, sua equipe, sua escola. Atividades que trabalhassem questões de gênero-sexualidade para além de uma perspectiva heteronormativa; que pudessem constituir uma oportunidade de multiplicação e experimentação, no ambiente da escola, das discussões sobre gênero, sexualidade e educação que eram realizadas no curso. Essas atividades foram realizadas durante a formação, com acompanhamento (ainda que precário) da equipe do curso. Cada cursista tinha muita liberdade (inclusive pela precariedade do acompanhamento) para planejar e realizar sua atividade, que podia se materializar de diferentes maneiras: uma aula regular, um evento, uma atividade no contraturno ou até mesmo uma transformação na estrutura ou organização da escola ou da sala de aula.

Para fins de avaliação - e de pesquisa - essas atividades eram registradas em um caderno que acompanhava cada cursista durante toda a formação. Isso produziu um considerável número de registros de atividades pedagógicas. Um rico material de pesquisa que tem permitido pensar sobre limites e oportunidades didáticas nesse campo.

\section{Analisando atividades pedagógicas e seus caminhos didáticos}

Em 2010, o curso teve 8 turmas em 6 municípios-pólo, mas nos detivemos apenas nos registros produzidos por profissionais das redes públicas de ensino da região metropolitana que se concentravam nas turmas de Rio de Janeiro, Nova Iguaçu $e$ Niterói. Ao todo, foram reunidos 37 cadernos, 21 produzidos por professores e professoras atuantes em sala de aula, 12 por 
diretoras ou coordenadoras pedagógicas e 4 por outras e outros profissionais de educação. Essas e esses profissionais atuavam em diferentes níveis de ensino (em alguns casos em mais de um): na educação infantil (12), no ensino fundamental (15), no ensino médio (9), na educação de jovens e adultos (8) e em cursos profissionalizantes (2). Nos cadernos analisados, foram registradas 34 atividades pedagógicas. Nos seus relatos, educadoras $e$ educadores descrevem suas experiências na tentativa de trabalhar, em seus contextos, os conceitos e perspectivas que eram discutidos no curso. Descrevem a reação de suas turmas, de suas alunas e alunos, de seus e suas colegas, trazendo muitos elementos interessantes para pensar sobre a materialização de uma perspectiva não heteronormativa no currículo e na prática pedagógica.

Como metodologia para interpretar os registros das atividades, trabalhei com análise de conteúdo (Bauer, 2008) identificando recorrências, semelhanças e distinções entre os textos, buscando especialmente os limites e oportunidades pedagógicas que os registros apontavam.

Diante de uma diversidade de experiências, minha primeira intenção foi tentar identificar não os métodos - grupos, trabalhos de pesquisa, aula expositiva -, nem os recursos - livros, vídeos ou jogos - utilizados em cada atividade, mas especialmente a abordagem. Abordagem no sentido de caminho didático, percurso que cada educadora escolheu para chegar à discussão sobre gênero-sexualidade. Algumas educadoras trabalharam a partir de casos de violência para iniciar uma discussão sobre homofobia $e$ machismo. Outras fizeram uma discussão a partir do conceito de família, problematizando a normatividade do modelo nuclear heterossexual $e$ visibilizando outros arranjos. Houve as que iniciaram uma reflexão a partir das ideias de diferença $e$ diversidade (sem muita distinção entre uma e outra) para então incluir as diferenças de gênero-sexualidade no debate. ${ }^{2}$

2 Para a análise completa de todas as atividades e categorias, consultar: Diversidade sexual na escola: currículo e prática pedagógica. Dissertação 
Já outras educadoras produziram atividades que pareciam investir diretamente na apresentação de um sujeito homossexual, gay ou lésbica, tendo esse sujeito como tema central da aula. Eram apresentadas à turma histórias $e$ imagens $e$ discutidas características que os definiriam. As aulas pareciam ter um objetivo informativo, como que descrevendo esse grupo de pessoas. É justamente a análise sobre esse conjunto de atividades que trago neste texto.

\section{Aula de hoje: homossexuais}

Vamos observar, na sequência, relatos de três educadoras que desenvolveram atividades exatamente nesse sentido. $\mathrm{O}$ primeiro é de uma professora do primeiro segmento do ensino fundamental da rede municipal de São João de Meriti:

Então dei início a minha intervenção.

- Crianças como percebemos se uma pessoa é gay ou não?

- Quando dois homens se abraçam na rua, tia.

Prontamente uma menina:

- Não tem nada a ver. Eu e a fulana andamos abraçadas na rua. Então isso quer dizer que eu sou biba?

Outra afirmou:

- Não tem nada a ver, só se eles estiverem se beijando na boca.

Foi o maior reboliço, porque todos já haviam presenciado a cena e queriam descrever o fato. Continuei:

- Crianças como podemos saber se um homem é gay?

-Pelo jeito de andar. E imitou, foi um riso geral.

- E como sabemos que uma mulher é lésbica?

- Tia, o que é isso?

- É quando uma mulher namora a outra.

- Ah! É sapatão, tia.

- Sim, mas continuando, como sabemos que ela é sapatão?

- Tia, pelo corte de cabelo!

(mestrado) - Pontifícia Universidade Católica do Rio de Janeiro, Departamento de Educação, 2012. 
E assim foram infinitas as respostas e, eu me senti realizada, havia conseguido falar com as crianças pequenas sobre homossexualismo sem agredi-los ou chocá-los. Então percebi que eles têm vivências a respeito do assunto.

Interessante como eles percebem através do jeito de andar, do corte de cabelo, pela roupa e até pelos adornos, entre outros.

A orientação sexual não é um tema fácil a ser abordado pela família, escola e pela sociedade.

Mas é possível quando procuramos abordar de forma clara, coerente e responsável. E sabermos exatamente onde devemos ir e recuar se necessário.

Em outro relato, uma professora de educação infantil da rede municipal de Nova Iguaçu descreve como deu uma aula sobre gays e lésbicas a partir de imagens em um cartaz que incluía ícones midiáticos - assumidamente ou apontados como homossexuais.

Trouxe para a Escola Municipal (...) um cartaz com várias figuras recortadas de revistas para trabalhar gênero com a minha turma do Infantil 5. De um lado do cartaz tinha figuras de homens, mulheres, crianças, barriga de grávida, só as pernas de uma passista de Escola de Samba (homem ou mulher), lésbica (Marlene Matos e Morango do Big Brother), gay (Serginho e Dicesar).

No terceiro relato, uma diretora de escola de educação infantil da rede municipal de Mesquita descreve uma atividade em que a imagem escolhida para introduzir o tema da homossexualidade foi uma apresentação em vídeo do cantor Ney Matogrosso cantando a música "O Vira".

A atividade foi realizada na turma de três anos $\mathrm{A}$, e o nosso objetivo era verificar se os nossos pequenos já possuíam alguma percepção sobre homossexualidade. Utilizamos o DVD "Ney Matogrosso - vivo", e apresentamos à turma a música "Vira" onde o cantor dança de forma bastante 
sensual, maquiado, com uma saia de tiras e adorno na cabeça com bastante pedras e brilhos. (...) Levei para as crianças uma roupa semelhante a do cantor $e$ propus reproduzirmos a cena. Foi um alvoroço só!

\section{A descrição do sujeito homossexual como caminho didático}

Sem dúvida seria importante fazer uma crítica dessas atividades baseada na proliferação de estereótipos que elas promovem. Mas, vou tentar conduzir uma reflexão crítica para, a partir dessas três experiências, pensar sobre o caminho didático que elas apontam, qual seja: investir na descrição do sujeito homossexual/gay/lésbica como estratégia para trabalhar questões de gênero-sexualidade numa perspectiva não-heteronormativa.

Essas estratégias didáticas parecem compartilhar alguns pressupostos:

1. o/a homossexual é um tipo;

2. essas pessoas compartilham algumas características que se expressam na forma como andam, agem, vestem, falam;

3. esse quadro de características é suficientemente estável e coerente a ponto de poder ser organizado e ensinado em uma aula.

Esse caminho didático, e os pressupostos em que ele se baseia - se retirados os estereótipos mais óbvios -, é um caminho em que outros grupos e profissionais vêm aparentemente apostando também. Por exemplo, o material em vídeo desenvolvido em 2011 (e nunca distribuído) pelo Ministério da Educação para combate à homobilesbotransfobia nas escolas faz exatamente esse investimento - cada vídeo vai apresentar e descrever a experiência de um sujeito (um adolescente bissexual, uma adolescente lésbica e uma adolescente transexual), no intuito de contribuir para a superação de preconceitos e discriminações na escola. ${ }^{3}$ Portanto, pensar sobre o caminho didático que essas

3 O material a que me refiro foi desenvolvido no âmbito do Programa Escola Sem Homobofia, que articulou diferentes organizações não governamentais $e$ instituições de pesquisa, com coordenação e financiamento do Ministério da 
experiências apontam, para além dos estereótipos que elas trazem, pode servir para uma reflexão mais ampla sobre outros investimentos semelhantes.

Fundo minha crítica problematizando quatro pontos principais:

- A diferença entre trabalhar um sujeito homossexual ao invés da homossexualidade como prática/desejo;

- A (im)possibilidade de definir qual a identidade homossexual legítima a ser ensinada;

- O foco na descrição estática e não no processo permanente de construção dos sujeitos e suas identidades;

- A limitação de se trabalhar apenas a homossexualidade, deixando de fora $e$, assim, reforçando a naturalização da heterossexualidade.

Dito isso, vamos tentar refletir sobre cada um desses pontos.

\section{O homossexual como sujeito ou a homossexualidade como prática?}

A primeira escolha das educadoras, aparentemente, foi ter como tema de aula não exatamente a homossexualidade, mas um sujeito homossexual. Talvez essa frase possa soar sem sentido. Afinal, falar sobre o sujeito homossexual não significa falar sobre

Educação. O material seria composto por cadernos didáticos e um conjunto de vídeos a serem distribuídos a educadoras de escolas públicas brasileiras, mas teve a sua finalização e distribuição vetadas diretamente pela Presidente Dilma Roussef em 2011, a partir da pressão de grupos religiosos representados no Congresso Nacional. Veto, portanto, que, na avaliação de muitos ativistas, jornalistas e acadêmicos, não teve nenhuma relação com a qualidade ou escolhas didáticas do material, mas com a histórica luta política entre setores que demandam o reconhecimento das diferentes possibilidades de vivência $e$ identidade de gênero-sexualidade e setores conservadores que defendem a hegemonia da heteronorma. Apesar do veto, os vídeos podem ser facilmente encontrados na internet a partir de uma simples busca pelos seus nomes: Torpedo, Encontrando Bianca e Probabilidade. 
homossexualidade? Falar sobre homossexualidade não significa obviamente falar de um sujeito homossexual? Ou não?

Até alguns séculos atrás, na cultura europeia - e provavelmente ainda hoje em determinados grupos e culturas - a homossexualidade - se podemos usar um conceito de hoje para falar de tempos antigos - era vista como uma prática, certa ou errada, mas uma prática, um ato, capaz de ser realizado a princípio por qualquer pessoa. Mesmo como um pecado ou um delito, era um pecado, nefando, ou um delito, repreensível, cometido por um ser humano qualquer. Num determinado momento histórico, aquilo que era um ato, passou a definir o próprio sujeito. $\mathrm{O}$ verbo se tornou substantivo. Como nos conta Foucault em um dos seus trechos mais clássicos:
A sodomia - dos antigos direitos civil ou canônico - era um tipo de ato interdito $e$ o autor não passava de seu sujeito jurídico. O homossexual do século XIX torna-se uma personagem: um passado, uma história, uma infância, um caráter, uma forma de vida; também é morfologia, com uma anatomia indiscreta e, talvez, uma fisiologia misteriosa. Nada daquilo que ele é, no fim das contas, escapa à sua sexualidade. (...) $\mathrm{O}$ sodomita era um reincidente, o homossexual é uma espécie (Foucault, 1999:50).

Assim, a partir especialmente da emergência do discurso científico sobre a sexualidade no século XIX, o que antes era apenas uma prática, vai se converter em uma categoria definidora de determinadas pessoas - e de muitas, como grupo. Essa construção do "sujeito homossexual" não é algo que ficou no passado, mas a origem histórica de muitas concepções que carregamos hoje e que opõe homossexuais e heterossexuais como naturezas distintas. Talvez por isso a professora de Nova Iguaçu distinga em seu cartaz gays/lésbicas de homens/mulheres (heterossexuais?). Talvez por isso, as educadoras não se proponham a dar uma aula sobre a homossexualidade enquanto prática ou experiência que pode ser experimentada por qualquer 
pessoa, mas sobre os/as homossexuais, enquanto um determinado "tipo de gente".

Essa escolha parece trazer algumas limitações - e algumas implicações. Restringir a homossexualidade - seja como desejo, seja como prática - apenas a homossexuais reforça uma demarcação rígida que não necessariamente condiz com a experiência de grande parte dos sujeitos. Afinal, não só sujeitos identificados como homossexuais, gays ou lésbicas vivenciam experiências ou desejos homoeróticos (e vice-versa).

Qual seria então $\mathrm{o}$ efeito se discutíssemos a homossexualidade como prática e não a/o homossexual como sujeito? Quais as implicações didáticas disso? Falar sobre a homossexualidade nesses termos talvez provocasse desconforto em boa parte dos sujeitos, ao perceberem a homossexualidade como uma prática ou um desejo possível a qualquer pessoa inclusive para si. Talvez tensionasse a "linha de segurança" que distingue homossexuais $e$ heterossexuais, recolocando $e$ ressignificando a diferença. E mais, talvez pudesse expandir a reflexão para além da homossexualidade, alcançando um debate sobre como a sexualidade como um todo é vivenciada, nas suas diferenças, nas suas tensões e nas suas contradições.

\section{Qual identidade homossexual vai ser ensinada?}

Pressupor que homossexuais sejam um "tipo de gente", aparentemente, implica pensar que eles e elas compartilham um determinado modo de agir, viver, pensar. Nos incômodos relatos das atividades, as professoras parecem buscar transmitir às suas alunas e alunos quem são esses sujeitos a partir de seus hábitos, suas expressões, seu jeito de ser. O objetivo das aulas parece ser ensinar quem são os homossexuais/gays/lésbicas. E elas parecem satisfeitas com o resultado e consideram que efetivamente cumpriram esse objetivo. Cumpriram? Se não, então, onde estaria o seu equívoco?

Poderíamos fazer uma crítica de que elas não foram bem sucedidas pelo fato de ensinarem esses sujeitos a partir de 
estereótipos. Estereótipos muito recorrentes no nosso contexto cultural e que confundem expressões de gênero com orientação sexual. O "erro" estaria então em ensinar de uma forma "errada" como são e vivem os gays e as lésbicas. Se essa é a crítica, a proposição decorrente dela poderia ser de que o caminho "certo" seria trabalhar "corretamente" as identidades gays e lésbicas, trazendo a verdadeira realidade desses sujeitos. Será?

Será que todas as pessoas que têm práticas ou desejos homossexuais compartilham um mesmo jeito de ser, de agir, de viver e mesmo de vivenciar a sua sexualidade (que é o que aparentemente lhes define)? Um jeito de ser descritivel em aula? Qual seria o jeito "certo" de ensinar quem são essas pessoas? Haveria um modo legítimo de falar sobre elas? Para além dos estereótipos mais óbvios, haveria um modo de trabalhar essas identidades de maneira correta, realista ou verossímil? O modelo identitário LGBT seria então o mais indicado? Haveria uma identidade legítima a ser ensinada e aprendida?

Se respondermos que, sim, há uma identidade homossexual legítima que pode - e deve - ser ensinada, teríamos que fazer uma nova pergunta: que identidade é essa? E uma outra, em consequência: quem diz que identidade é essa? Se há uma identidade legítima, a disputa pode passar a ser justamente por definir qual é. E nessa disputa há sempre a possibilidade de cairmos na construção de uma hierarquia que diz quê expressão dentre as diversas possibilidades de experiência desses tão diferentes sujeitos vai ter mais valor e será eleita como modelo identitário para todo o grupo. E não é difícil imaginar quanto machismo, elitismo e racismo marcam a escolha de quem vai ser a referência.

Muitas políticas públicas desenvolvidas hoje em diferentes áreas, inclusive na educação (Mello, 2010) têm como base um determinado modelo identitário - LGBT: lésbicas, gays, bissexuais, travestis e transexuais $-e$ a promoção do seu reconhecimento. Essas identidades atingiram esse grau de "legitimidade" a partir de intensas lutas políticas de movimentos sociais que foram não só demandando reconhecimento, mas formulando, reformulando $e$ 
negociando os termos desse reconhecimento. O modelo identitário LGBT não esteve sempre aí, ele é uma construção bastante recente (Facchini, 2005).

Será então que esse modelo identitário - mesmo sem os estereótipos e estigmas - contempla as experiências de gênerosexualidade que encontramos hoje na escola - e fora dela? Será que podemos trabalhar na perspectiva de que todas as pessoas que têm práticas e desejos homossexuais podem se encaixar em algumas opções identitárias previamente oferecidas? Mulheres $e$ homens trans vão vivenciar a experiência da homossexualidade de maneira muito distinta (entre si e) de homens e mulheres cujo corpo e identidade de gênero nunca foram (tão enfaticamente) questionados. Muitas e muitos heterossexuais (porque assim se identificam e não me cabe lhes questionar a identidade) vão vivenciar experiências sexuais e afetivas com pessoas do seu mesmo gênero, sem fazer disso uma identidade. Quando as professoras se propõem a dar uma aula sobre quem são as pessoas homossexuais, quanto estão descrevendo uma diversidade de experiências (e aprendendo com elas)? E quanto estão reiterando apenas um número muito pequeno de possibilidades como modelo da experiência homossexual? E se muitos sujeitos que vivenciam práticas e desejos homossexuais não se reconhecerem (cada vez mais) nesses modelos? Não seria limitador trabalhar numa perspectiva LGBTista? Mesmo que afirmada historicamente como parte de um processo de subversão à norma $e$ às suas violências, uma identidade, se convertida em modelo, pode acabar produzindo novas restrições ao viver e estar no mundo, aprisionando seus próprios inventores e limitando sua experiência.

\section{Identidade em movimento}

Nas suas aulas, as professoras parecem falar desses sujeitos entendendo suas sexualidades e identidades como acabadas. Será? Prefiro apostar na perspectiva de que nossa identidade não é algo que já nasça pronto nem que se consolide definitivamente 
num certo momento da vida, mas, ao contrário, é identidade permanentemente e reiteradamente construída. Permanentemente porque é um processo social contínuo, vivenciado individual $e$ coletivamente a todo momento. Reiteradamente porque é produto de uma série de reiterações cotidianas: discursos e práticas de que somos agente-objeto $e$ que se repetem sistemática $e$ sistemicamente - e é justamente esse conjunto de reiterações cotidianas que cria a ilusão de uma identidade estável (Butler, 2000). Isso significa dizer que nossa identidade não foi construída, mas que está sendo, a todo momento. Que ela não é estado, mas processo. Processo complexo e vivo que só pode parecer estático na análise.

Os relatos nos fazem pensar sobre como pode ser limitador investir em estratégias didáticas descritivas - que logo têm grandes chances de se tornar prescritivas. Tanto porque elas limitam o entendimento e mesmo a experiência dos sujeitos - ao persistir em modelos, normatividades e invisibilizações - quanto porque ela é incompetente, ao oferecer sempre uma descrição estereotipada, atrasada ou restrita de um universo muito mais rico e amplo que qualquer capítulo de livro é capaz de conter. Mas será possível falar de experiências, vivências e sujeitos fora dos padrões da heteronorma sem que tenhamos um quadro identitário de referência? Roubando a pergunta de Guacira Lopes Louro, em um campo tão dado à normatização, classificação, formatação como o da Educação, é possível pensar uma didática pósidentitária (Louro, 2001)?

Se a experiência sexual-de gênero é um processo que incide sobre a própria construção dos sujeitos e suas identidades, e se gênero-sexualidade é ação, talvez um caminho seja visibilizar esse nosso fazer que vai nos constituindo. Não há como uma foto explicar algo que é fundamentalmente movimento. Então que tal apontar onde, como e quando somos agente e objeto no processo de construção da nossa própria sexualidade. Como as diferentes pessoas vão viver de diferentes e múltiplas formas esse processo e produzir diferentes identidades. Como as relações de poder vão incidir na construção das nossas identidades, num jogo que 
articula normatização e subversão. Como a construção dessas identidades sexuais-de gênero é processo social, individual $e$ coletivo, vivenciado permanente e reiteradamente por todas as pessoas.

\section{Aprendendo sobre os homossexuais. E sobre os heterossexuais? Não?}

Na maior parte das atividades analisadas, o que está em questão são as pessoas homossexuais (num entendimento consideravelmente restrito e estereotipado), e não a experiência da sexualidade (na qual a homossexualidade - em suas diferentes possibilidades de vivência - também é parte). E esses sujeitos parecem estar colocados no lugar do outro, daquele que não somos nós. Dar uma aula sobre "as e os homossexuais" como o outro que precisa ser conhecido, desvendado, não seria reiterar um lugar marginal para as pessoas que vivenciam práticas $e$ desejos homossexuais - em especial para aquelas para quem essa experiência é decisiva e se converte mesmo em identidade? Falar apenas "das e dos homossexuais" não seria colocar essas pessoas no lugar (exótico) do outro? Afinal, quem é o nós? Quem são os outros?

Quando as atividades focam apenas o sujeito homossexual, podem acabar reafirmando a heterossexualidade no lugar do óbvio, natural, normal, a tal ponto que ela não precisa ser em si estudada. Isso não significa dizer que a heterossexualidade está sendo invisibilizada nas aulas que foram relatadas. Ao contrário, ela paira acima das discussões, como norma que não faz sentido ser questionada, como referência de normalidade $e$ de identificação. E desse lugar ela se contrapõe hierarquicamente à homossexualidade (ao mesmo tempo em que contrapõe heterossexuais a homossexuais), reiterada no lugar da diferença.

Se o silêncio sobre a homossexualidade contribui para blindar a heterossexualidade de qualquer reflexão crítica sobre si, reforçando a sua naturalização, colocar a homossexualidade no lugar da diferença pode ser outra forma de manter inquestionada 
(e inquestionável) a heterossexualidade. A homossexualidade aparece como fenômeno extraordinário, que salta aos olhos em uma paisagem saturada de heterossexualidade. A heterossexualidade é o natural e o óbvio. E o que é natural $e$ óbvio não precisa ser discutido. Ou mais do que isso, para que algo siga sendo natural e óbvio, é imprescindível que não seja discutido.

Grande parte do investimento político para barrar debates sobre a homossexualidade na escola não visa apenas impedir que crianças ou adolescentes pensem, falem, discutam a homossexualidade, mas também que eles e elas não possam pensar, falar ou discutir sobre a própria heterossexualidade. Como a sua heterossexualidade foi construída, como a sua heterossexualidade é reiterada, quais as potências e os limites que eles e elas vivenciam na heterossexualidade. Como a sexualidade marca também sua construção de gênero, sua relação com o masculino e o feminino. Pensar a homossexualidade restrita a "os $e$ as homossexuais" marcados e marcadas como diferentes não é necessariamente perigoso para a hegemonia heteronormativa. Perigoso é quando esse pensar acaba produzindo uma reflexão sobre as práticas e discursos que produzem as relações, representações e identidades de gênero-sexualidade. Não só a de pessoas que vivenciam a homossexualidade. Não só a dos outros. Mas a minha e a sua também.

Então talvez seja mais interessante investir em experiências pedagógicas que permitam o contato com múltiplas possibilidades de vivência de gênero-sexualidade - sem enclausurar ninguém como a diferença, mas investindo na percepção de que a sua experiência é uma dentre diversas (semelhantes e diferentes) possibilidades - e que é possível aprender sobre o outro e, mais ainda, sobre si mesmo na relação com o outro. Talvez um desafio interessante seja tornar a heterossexualidade questão de aula. Não como algo dado, óbvio ou naturalizado, mas ela também como construção social. Pensar sobre a homossexualidade implica também pensar sobre a heterossexualidade, sobre como esse modelo binário marca a nossa experiência $e$ as nossas 
representações, sobre como essa dicotomia é parte de um complexo chamado heteronormatividade, que faz com que gênero e sexualidade se articulem produzindo corpos, identidades e uma determinada forma de organização social.

\section{Buscando conclusões}

Este trabalho de pesquisa - do qual trazemos aqui apenas um recorte - rendeu alguns aprendizados. Diferentes abordagens propostas por educadores e educadoras - de algum modo inovadoras - mostraram limites e oportunidades, e como mesmo educadoras trabalhando na intenção de valorização de sujeitos marginalizados pela heteronorma são capazes de tropeçar diversas vezes em discursos, representações e práticas heteronormativas tão naturalizadas e internalizadas que se tornam invisíveis ao primeiro olhar (e talvez mesmo ao segundo, ao terceiro...).

Muito além da busca por respeito e vago pluralismo, vale discutir e abalar códigos dominantes de significação, desestabilizar relações de poder, fender processos de hierarquização, perturbar classificações e questionar a produção de identidades reificadas e diferenças desigualadoras (Junqueira, 2011:89).

Há aqui também uma questão que diz respeito não só à nossa compreensão sobre gênero-sexualidade, mas que evoca uma discussão filosófica própria do campo da educação: se educar é transmitir um conhecimento dado e fechado sobre coisas e pessoas ou um processo de leitura crítica e mobilizadora do mundo e de si mesmo (Freire, 1996). O aprendizado sobre o mundo e sobre o outro é sempre um aprendizado sobre si. Um processo que não se inicia nem termina na sala de aula, mas no qual a escola tem uma importância única, pela sua capacidade de provocar o contato com a diferença $e$ a multiplicidade de experiências, de discursos, de sujeitos e de possibilidades. Mas como então construir estratégias didáticas que invistam no reconhecimento e na valorização das diferenças de gênero- 
sexualidade - e no aprendizado sobre si e sobre o outro através delas?

As atividades pedagógicas que vimos parecem ter o objetivo de visibilizar determinados grupos, tornando-os mais inteligíveis às $e$ aos estudantes. Talvez de fato um dos primeiros investimentos tenha a ver com inteligibilidade. Tornar compreensíveis corpos, práticas, histórias e sujeitos invisibilizados. Colocar-se diante de um outro diferente de si. Fazer exercícios de tradução - para todos os lados - que permitam que os sujeitos interajam. E na interação, aprendam.

\section{(...) para sermos capazes de relativizar nossa própria maneira de situar-nos diante do mundo e atribuir-lhe sentido é necessário que experimentemos uma intensa interação com diferentes modos de viver e expressar-se. Não se trata de momentos pontuais, mas da capacidade de desenvolver projetos que suponham uma dinâmica sistemática de diálogo e construção conjunta entre diferentes pessoas e/ou grupos de diversas procedências sociais, étnicas, religiosas, culturais, etc. (Candau, 2008:54).}

Esse investimento se constitui em um aprendizado que tem a ver não só com conhecimento, mas com vivências, convivências e experiências compartilhadas. Não só com aprender sobre, mas aprender com. E reconhecer o lugar do outro provoca reconhecer o nosso próprio lugar. O outro é sempre o outro de mim. E eu também sou seu outro. Mas o outro precisa ser conhecido na sua complexidade (e eu também). Mesmo que se supere uma perspectiva obviamente estereotipada, qualquer descrição que se pretenda totalizadora de um grupo de sujeitos é sempre limitada e reducionista. E pode acabar se transformando em um exercício prescritivo. Por isso é importante trabalhar com a experiência dos sujeitos em sua diferença e diversidade. Pensar a construção de identidades de gênero-sexualidade não a partir de modelos préestabelecidos, mas a partir das experiências e vivências concretas das pessoas no processo de construção e de afirmação de suas identidades. 
Mesmo com todas as críticas, é preciso reconhecer a singular importância do trabalho de experimentação dessas educadoras. Já sabemos muito sobre o que não devemos fazer, mas ainda há muito que descobrir sobre o que deve ser feito e como fazê-lo. Se não há caminho certo, o que ainda há, certamente, é um longo caminho a ser percorrido, não apenas na desconstrução das violências e desigualdades de gênero-sexualidade na escola, mas na construção de uma pedagogia não heteronormativa. E superar a violência e a discriminação das relações interpessoais é só o início do processo, embora seja um urgente começo. A construção de uma nova forma de trabalhar gênero-sexualidade na educação não virá apenas da academia, mas terá de ser construída na prática pedagógica de educadoras e educadores. Uma construção que se faz experimentando, errando, acertando, refletindo, repensando, criando e recriando nossas práticas e a nós mesmos.

\section{Referências bibliográficas}

AUAD, Daniela. Relações de gênero nas práticas escolares e a construção de um projeto de co-educação. In: Anais do $27^{\mathrm{a}}$. Reunião da ANPED, Caxambu - MG, 2004.

BAUER, Martin. Análise de conteúdo clássica: uma revisão. In: BAUER \& GASKELL. Pesquisa qualitativa com texto, imagem e som. Petrópolis, Vozes, 2008, pp.189-217.

Bortolini, Alexandre. Diversidade Sexual na Escola: Currículo e Prática Pedagógica. Dissertação de mestrado, Educação, PUC-Rio, 2012 [www.pr5.ufrj.br/diversidade].

ButLER, Judith. Problema de Gênero: feminismo e subversão da identidade. Rio de Janeiro, Civilização Brasileira, 2003.

. Corpos que pesam: sobre os limites discursivos do "sexo". In: Louro, Guacira Lopes. (org.). O Corpo Educado: Pedagogias da sexualidade. Belo Horizonte, Autêntica, 2000.

CANDAU, Vera Maria (org). Educação Multicultural: Tendências e Propostas In: Sociedade, Educação e Cultura(s). Petrópolis, Editora Vozes, 2010. 
Direitos humanos, educação e interculturalidade: as tensões entre igualdade e diferença. Revista Brasileira de Educação, Anped, Rio de Janeiro, vol. XIII, n 37, 2008, pp.45-56.

CARRARA, Sérgio; RAmOS, Silvia. Política, direitos, violência e homossexualidade. Pesquisa $9^{a}$ Parada do Orgulho GLBT - Rio 2004. Rio de Janeiro, CEPESC, 2005.

CASTRO, Mary; ABramovay, Miriam; SILVA, L. B. Juventudes e sexualidade. Brasília, UNESCO, 2004.

FACCHINI, Regina. Sopa de Letrinhas?: movimento homossexual e produção de identidades coletivas nos anos 1990. Rio de Janeiro, Garamond, 2005.

FERRARI, Anderson. "O que é loba??? É um jogo sinistro, só para quem for homem..." - gênero e sexualidade no contexto escolar. In: Anais do 30a. Reunião da ANPED, Caxambu - MG, 2007.

Foucault, Michel. História da Sexualidade I: A Vontade de Saber. Rio de Janeiro, Edições Graal, 1999.

Freire, Paulo. Pedagogia da Autonomia. São Paulo, Paz e Terra, 1996.

FREITAS, Lígia Luís de. Gênero e futebol feminino: preconceitos, mitos e sexismo na prática discursiva de docentes da educação física. In: Anais do 27a. Reunião da ANPED, Caxambu - MG, 2004.

FURLANI, Jimena. O Bicho vai pegar! - um olhar pós-estruturalista à Educação Sexual a partir de livros paradidáticos infantis. Tese de Doutorado apresentada ao Programa de Pós-Graduação em Educação da Faculdade de Educação da Universidade Federal do Rio Grande do Sul. Porto Alegre, UFRGS, 2005.

JUNQUEIRA, Rogério Diniz. Diversidade sexual e homofobia: a escola tem tudo a ver com isso. In: XAVIER FILHA, Constantina (org.). Educação para a sexualidade, para a equidade de gênero e para a diversidade sexual. Campo Grande, UFMS, 2009c, pp.111-142.

. Heterossexismo e vigilância de gênero no cotidiano escolar: a pedagogia do armário In: Silva, F. F.; Mello, E. M. B. (Org.). Corpos, gêneros, sexualidades e relações étnico-raciais na educação. Uruguaiana: UNIPAMPA, 2011, pp.74-92. 
LionçO, Tatiana; DinIZ, Débora. (orgs.). Homofobia \& Educação: um desafio ao silêncio. Brasília, LetrasLivres/EdUnB, 2009.

LOURO, Guacira Lopes. Teoria queer: uma política pós-identitária para a educação. Revista Estudos Feministas, vol.9, n.2, pp.541-553, 2001 [http://dx.doi.org/10.1590/S0104-026X2001000200012 - acesso em: 10 mai 2010].

Mazzon, José. A. Ações Discriminatórias no âmbito escolar. Relatório de Pesquisa. São Paulo, MEC-INEP e FIPE-USP, 2009.

Mello, Luiz. (Org.). Políticas Públicas para a população LGBT no Brasil: um mapeamento crítico preliminar: Relatório de Pesquisa. Goiânia, UFG, Faculdade de Ciências Sociais, SerTão, Núcleo de Estudos e Pesquisas em Gênero e Sexualidade, 2010.

SILVA, Mirian. Quando o estranho é o professor: narrativas sobre sexualidade e o currículo de formação de professores. In: Anais do 30a. Reunião da ANPED, Caxambu - MG, 2007. 